\title{
Article \\ Fluctuating Asymmetry and Sexual Dimorphism in Human Facial Morphology: A Multi-Variate Study
}

\author{
Omid Ekrami ${ }^{1, *}{ }^{\mathbb{D}}$, Peter Claes ${ }^{2,3,4}{ }^{\mathbb{D}}$, Ellen Van Assche ${ }^{1}$, Mark D. Shriver ${ }^{5}$, Seth M. Weinberg ${ }^{6,7}$, \\ Mary L. Marazita ${ }^{6,7}$, Susan Walsh ${ }^{8}$ (D) and Stefan Van Dongen ${ }^{1}$ (D) \\ 1 Evolutionary Ecology Group, Department of Biology, University of Antwerp, 2610 Antwerp, Belgium; \\ ellen.vanassche@student.uantwerpen.be (E.V.A.); stefan.vandongen@uantwerpen.be (S.V.D.) \\ 2 Department of Electrical Engineering, ESAT/PSI, KU Leuven, 3000 Leuven, Belgium; peter.claes@kuleuven.be \\ 3 Medical Imaging Research Center, UZ Leuven, 3000 Leuven, Belgium \\ 4 Department of Human Genetics, KU Leuven, 3000 Leuven, Belgium \\ 5 Department of Anthropology, Pennsylvania State University, University Park, PA 16801, USA; \\ mds17@psu.edu \\ 6 Center for Craniofacial and Dental Genetics, Department of Oral and Craniofacial Sciences, University of \\ Pittsburgh, Pittsburgh, PA 15261, USA; smwst46@pitt.edu (S.M.W.); marazita@pitt.edu (M.L.M.) \\ 7 Department of Human Genetics, Graduate School of Public Health, University of Pittsburgh, \\ Pittsburgh, PA 15261, USA \\ 8 Department of Biology, Indiana University Purdue University Indianapolis (IUPUI), \\ Indianapolis, IN 46202, USA; walshsus@iupui.edu \\ * Correspondence: omid.ekrami@uantwerpen.be
}

Citation: Ekrami, O.; Claes, P.; Van Assche, E.; Shriver, M.D.; Weinberg, S.M.; Marazita, M.L.; Walsh, S.; Van Dongen, S. Fluctuating Asymmetry and Sexual Dimorphism in Human Facial Morphology: A Multi-Variate Study. Symmetry 2021, 13, 304. https://doi.org/10.3390/sym13020304

Academic Editor: John H. Graham

Received: 8 December 2020

Accepted: 8 February 2021

Published: 10 February 2021

Publisher's Note: MDPI stays neutral with regard to jurisdictional claims in published maps and institutional affiliations.

Copyright: (C) 2021 by the authors. Licensee MDPI, Basel, Switzerland. This article is an open access article distributed under the terms and conditions of the Creative Commons Attribution (CC BY) license (https:/ / creativecommons.org/licenses/by/ $4.0 /)$
Abstract: (1) Background: Fluctuating asymmetry is often used as an indicator of developmental instability, and is proposed as a signal of genetic quality. The display of prominent masculine phenotypic features, which are a direct result of high androgen levels, is also believed to be a sign of genetic quality, as these hormones may act as immunosuppressants. Fluctuating asymmetry and masculinity are therefore expected to covary. However, there is lack of strong evidence in the literature regarding this hypothesis. (2) Materials and methods: In this study, we examined a large dataset of high-density 3D facial scans of 1260 adults (630 males and 630 females). We mapped a highdensity 3D facial mask onto the facial scans in order to obtain a high number of quasi-landmarks on the faces. Multi-dimensional measures of fluctuating asymmetry were extracted from the landmarks using Principal Component Analysis, and masculinity/femininity scores were obtained for each face using Partial Least Squares. The possible correlation between these two qualities was then examined using Pearson's coefficient and Canonical Correlation Analysis. (3) Results: We found no correlation between fluctuating asymmetry and masculinity in men. However, a weak but significant correlation was found between average fluctuating asymmetry and masculinity in women, in which feminine faces had higher levels of fluctuating asymmetry on average. This correlation could possibly point to genetic quality as an underlying mechanism for both asymmetry and masculinity; however, it might also be driven by other fitness or life history traits, such as fertility. (4) Conclusions: Our results question the idea that fluctuating asymmetry and masculinity should be (more strongly) correlated in men, which is in line with the recent literature. Future studies should possibly focus more on the evolutionary relevance of the observed correlation in women.

Keywords: fluctuating asymmetry; 3D morphometrics; sexual dimorphism

\section{Introduction}

Sexual dimorphism and symmetry in human faces have both been proposed to signal an individual's genetic quality [1-4]. Bilateral symmetry is believed to reflect an individual's ability to block out genetic stress and environmental perturbations during their development [5]. The inability to block out these genetic and environmental stressors is referred to as Developmental Instability (DI). Therefore, Fluctuating Asymmetry (FA), 
defined as directionally-random small perturbations from perfect symmetry, is often used as an indicator of DI, and is expected to show a negative correlation with the genetic quality of an organism. Following this hypothesis, FA has been extensively studied in the human face and body [2,6,7], as well as in animals [8-10]. However, studies that have investigated this possible link have often reported weak or non-existent correlations, even though, on average, a robust and significant correlation exists [7].

The sexual dimorphism in human faces (masculinity in men and femininity in women) is a result of high levels of androgen. Masculinity is often escribed as wide faces with a wide inter-orbital distance, a wide nose, thin lips, a large and massive lower face, and prominent cheek bones in men [11]. Androgen is thought to act as an immunosuppressant [12]. Accordingly, individuals who can withstand this extra cost caused by the immunosuppression are believed to be of higher genetic quality. This is known as the Immunocompetence Handicap Hypothesis (ICHH) [13]. However, Roberts et al. (2004) [14] challenges the ICHH, reporting no effect of testosterone on immunity in men. Similarly to FA, several studies have also examined the hypothesized correlation between masculinity, genetic quality and attractiveness [15-18]; however, the reported findings are contradictory and not definitive, especially in men. Naturally, the ICHH applies in cases where the levels of androgen fall within the 'normal' range. Excessive levels of androgen, known as hyperandrogenism, can have negative effects on human health.

Another measure that could possibly link FA and masculinity is attractiveness, i.e., qualities that are desirable in a mate. In an evolutionary context, FA and attractiveness are hypothesized to show a negative correlation, as individuals with 'good genes' are believed to appear more attractive to their potential mates. While some studies have reported statistically significant correlations between FA and attractiveness [19-22], a meta-analysis of the findings questions the meaningfulness of the reported evidence [7]. The link between masculinity and attractiveness is also not that clear. While some studies have found evidence that higher levels of sexual dimorphism are perceived as more attractive [19,23], others have found evidence supporting the opposite [24,25]. It is also believed that a preference for masculine men can be condition-dependent in women $[4,26]$.

Despite the limited evidence, sexual dimorphism and FA are believed to point to a shared underlying quality measure in which, in males and females, a negative association between FA and masculinity or femininity, respectively, is expected. While some studies have reported evidence supporting this negative correlation [2,27], others have not found any correlation between FA and masculinity $[4,28]$. A meta-analysis on these studies found little, if any, evidence of correlation between sexual dimorphism and developmental instability [29]. Furthermore, Puts (2010) [30] argued that the regulation of androgen levels and the response to them may have evolved in such a way that sexually-selected traits are developed in proportion to a male's ability to safely bare them, in which case no correlation would be expected between FA and masculinity levels. However, these scenarios are not mutually exclusive, and can happen within the same population [29]. It is worth mentioning that, as discussed above, FA is a result of both genetic and environmental stressors. However, in this study, we only focus on the genetic aspect, as it is more relevant when we discuss correlation with masculinity.

Perhaps one of the reasons behind the contradicting and ambiguous results so far is that each of these studies uses a different set of measures to represent FA. Furthermore, most of the studies follow the conventional method for measuring FA. This is performed by assigning anatomically meaningful landmarks to $2 \mathrm{D}$ photographs and comparing the corresponding landmarks on both sides of a trait, after correcting the measurements for average asymmetry (known as Directional Asymmetry, or DA). The use of 2D photographs automatically ignores a third dimension that might present valuable information regarding asymmetry or sexual dimorphism. Additionally, these photographs were not taken using a standardized method, and corrections for size differences were only performed using a single linear measure, which may not be representative for a complex structure like the human face [4]. It is thus clear that a more standardized and in-depth look into the possible 
correlation between FA and masculinity is needed. In this study, we use high-density 3D scans of human faces to examine the correlation between FA and masculinity, and their possible common underlying mechanism [31]. We estimate the hyper-dimensional measures of FA and masculinity in faces, and investigate the possible correlations between these two measures in a multi-variate context [32]. Moreover, the expected strength of associations are likely to be small, such that high sample sizes are required [33], which we obtained for this study.

\section{Materials and Methods}

A large dataset of high-density 3D facial scans of 1260 adults (630 males and 630 females) were used in this study. The subjects were all between 18 to 35 years old, with a BMI within the normal range $\left(18.5\right.$ to $\left.24.9 \mathrm{~kg} / \mathrm{m}^{2}\right)$. All of the participants identified themselves as being of European descent, and none of them reported any condition that might have altered their facial structure. These scans originated from a mixture of several studies at the University of Pittsburgh, Pennsylvania State University, and Indiana University-Purdue University, Indianapolis, and were captured using two stereo-photogrammetry systems: the VECTRA H1 camera (Canfield Scientific, Parsippany, NJ, USA) and the 3dMDface system (3dMD, Atlanta, GA, USA). The gathering of the facial scan data was approved by the relevant local ethics committees.

All of the scans were processed and transformed into a homogenous configuration of quasi-landmarks following Ekrami et al. (2018). In this approach, a high-density anthropometrical mask, consisting of $n=7160$ paired quasi-landmarks, was mapped onto each face using a non-rigid Iterative Closest Points (ICP) algorithm. This algorithm resembles the stretching of an elastic mask onto each face and re-forming it until the mask takes the shape of the face. This allows us to represent all of the faces using the same structure of corresponding quasi-landmarks, which enables us to use standardized statistical analyses on the dataset. Although the age range of our subjects places them all in the same physiological reproduction group, there could still be morphological differences due to age. We corrected the effect of age on the morphology of the faces by regressing the obtained quasi-landmarks on age, and using the residuals to make sure age does not play a role in our analysis.

We then used a Partial Least Squares (PLS) analysis to find the hyper-plane that best explains the correlation between the quasi-landmark coordinates and sex of the participants. Then, by projecting the facial scans onto this hyper-plane, we obtained individual masculinity scores for each face. The distribution of the centralized and normalized masculinity scores are shown in Figure 1. Higher masculinity scores thus reflect more masculine faces in men and women, and a substantial overlap of the scores is observed between -0.2 and 0.2 (Figure 1).

The fluctuating asymmetry of the faces was calculated as the corrected FA (C-FA) measure, following Ekrami et al. (2020). As described in that paper, removing the population average asymmetry from the total asymmetry, as is conventionally performed to obtain FA, does not completely correct for the effects of Directional Asymmetry (DA) on the asymmetry measurements at an individual level. Therefore, a new measure of asymmetry, the so-called Fluctuating Directional Asymmetry (F-DA), is used to individually correct the effect of DA on each face. The F-DA vector of a face is defined as the projection of the face onto the population-level DA vector. The corrected FA is then calculated by removing the F-DA vector from the conventionally-obtained FA vector.

In order to explore the different dimensions of fluctuating asymmetry, we used Principal Component Analysis (PCA) to break down the C-FA space (the space defined by the C-FA vectors) into its main dimensions of variation (Figure 2). We used the first five principal components (PC) (explaining about $60 \%$ of the variations in C-FA) for our analysis. Because of the hyper-dimensional nature of our FA measure, the remainder of the variation (about $40 \%$ ) is split up between thousands of PCs, each containing a very small fraction of the variation. Hence, it is not easy to decide on a cut-off point for the PCs 
to be considered in our analysis. However, if the first 5 PCs don't show any significant correlation to masculinity, we can deduce that the rest of the PCs are also very unlikely to contain any meaningful information.

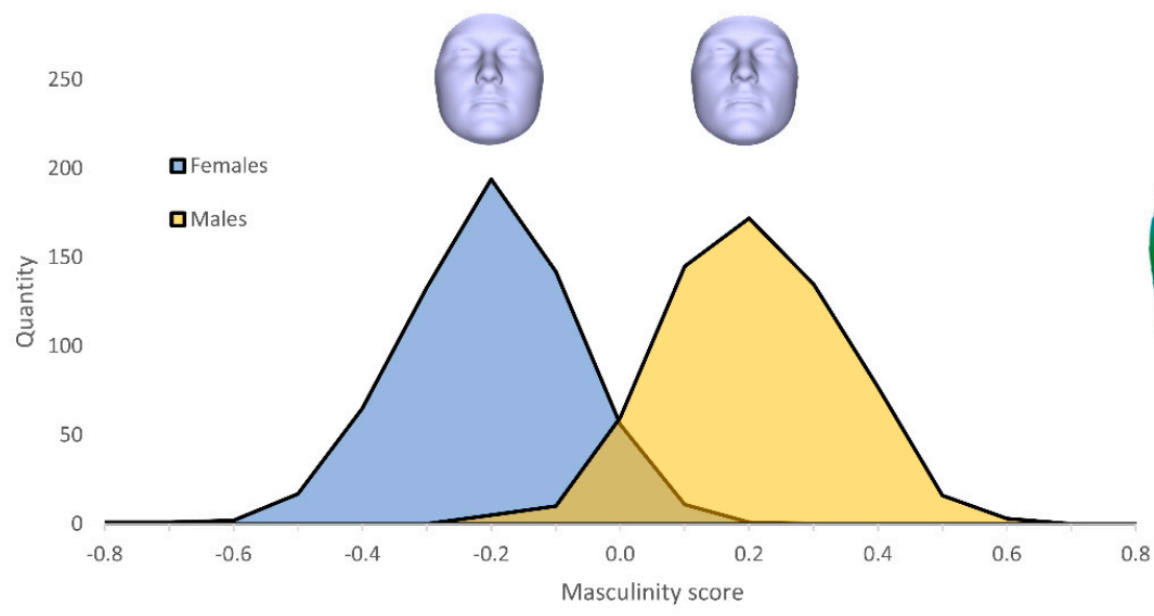

(a)

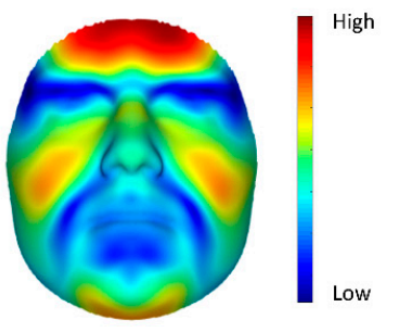

(b)

Figure 1. Variation in facial masculinity. (a) The distribution of masculinity scores in men and women. The scores are normalized in the range $[-1,1]$, and are centralized around zero. (b) A heat-map showing the regions of difference between the average male and average female face. The blue regions show no or low difference between the average male and female, while the red regions correspond to high difference. As is evident from the figure, the morphological differences are more prominent in the forehead, the cheeks, and the chin regions.

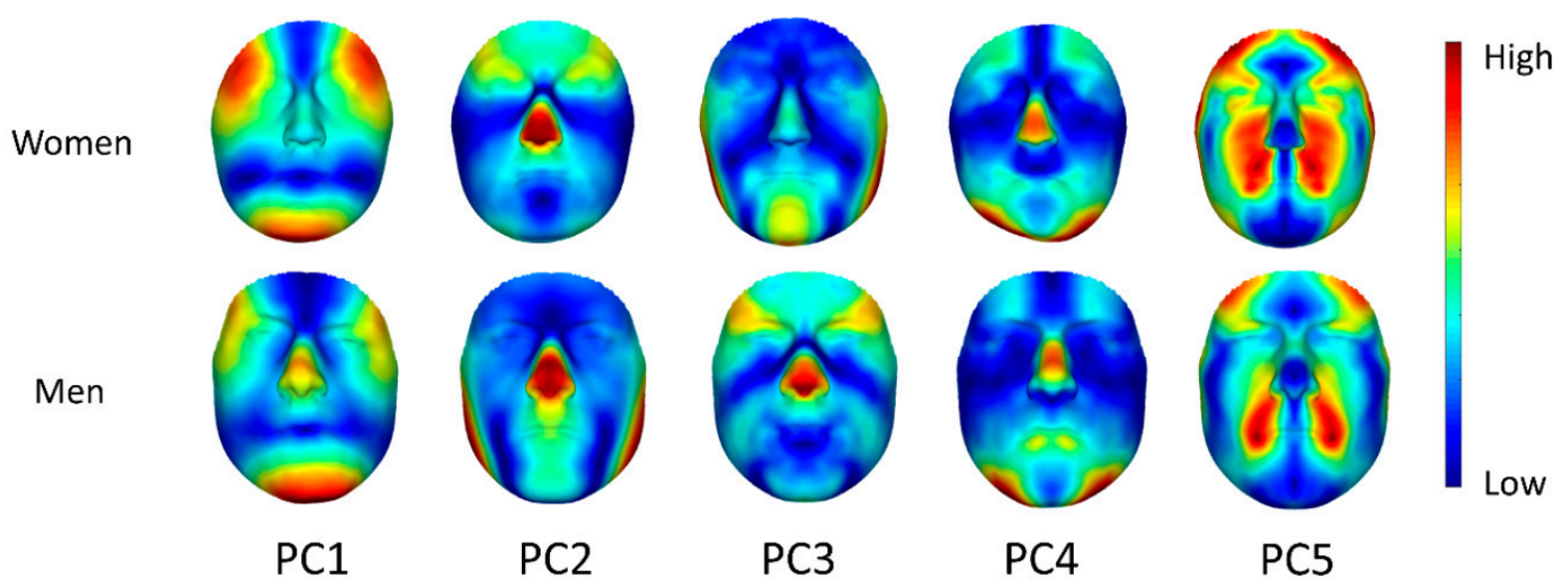

Figure 2. Heat map of the first five PCs of C-FA for both males and females. Each column represents a different dimension of variation of FA in women and men separately. The blue color indicates no FA in those regions, and going towards red means more FA. We can see that the patterns of variation in the PCs corresponds between the two groups, except for PC2 and PC3, which have switched places between men and women (PC2 in women corresponds to PC3 in men, and PC2 in men corresponds to PC3 in women). The variations are amplified for visual purposes.

In total, we used six measures to represent FA in each face, i.e., the average C-FA and the first five PC scores for the C-FA space. The associations between these measures and the sexual dimorphism scores were calculated as Pearson correlation coefficients in men and women separately. Additionally, we used Canonical Correlation Analysis (CCA) to measure the multivariate correlation between the six measures of fluctuating asymmetry and the sexual dimorphism scores. 


\section{Results}

We found a statistically significant positive correlation between average C-FA and masculinity in women (Table 1, Figure 3). None of the PCs showed any significant correlation with the masculinity scores in women. Thus, less feminine faces were on average more asymmetric, but no significant correlation was found in any of the 5 extracted FA dimensions. We did not find any significant correlations between the average C-FA or any of the PCs of the C-FA space with the masculinity scores in men, and all of the estimates were, overall, small. There was also no correlation found between the absolute value of the individual measure of DA (F-DA) and masculinity in men or women.

Table 1. Correlations between masculinity scores and different measures of FA in men and women. The Pearson's coefficient (r), $p$-values, and 95\% confidence intervals are reported. The significant results are printed in bold.

\begin{tabular}{ccccccc}
\hline & Men & & & \multicolumn{2}{c}{ Women } \\
\hline & $\begin{array}{c}\text { Pearson } \\
\text { Coefficient }\end{array}$ & $p$ & C.I (95\%) & $\begin{array}{c}\text { Pearson } \\
\text { Coefficient }\end{array}$ & $p$ & C.I (95\%) \\
\hline Average C-FA & 0.05 & 0.22 & $(-0.02,0.12)$ & $\mathbf{0 . 1 1}$ & $\mathbf{0 . 0 0 6}$ & $\mathbf{( 0 . 0 3 , \mathbf { 0 . 1 8 } )}$ \\
PC1 & 0.07 & 0.062 & $(-0.00,0.15)$ & 0.05 & 0.237 & $(-0.03,0.12)$ \\
PC2 & 0.06 & 0.109 & $(-0.01,0.14)$ & 0.05 & 0.210 & $(-0.03,0.12)$ \\
PC3 & 0.03 & 0.331 & $(-0.03,0.11)$ & 0.07 & 0.083 & $(-0.00,0.14)$ \\
PC4 & -0.05 & 0.153 & $(-0.13,0.02)$ & 0.05 & 0.146 & $(-0.02,0.13)$ \\
PC5 & -0.02 & 0.528 & $(-0.10,0.05)$ & 0.00 & 0.898 & $(-0.07,0.08)$ \\
IF-DA & 0.07 & 0.055 & $(-0.00,0.15)$ & 0.06 & 0.129 & $(-0.01,0.13)$ \\
\hline
\end{tabular}

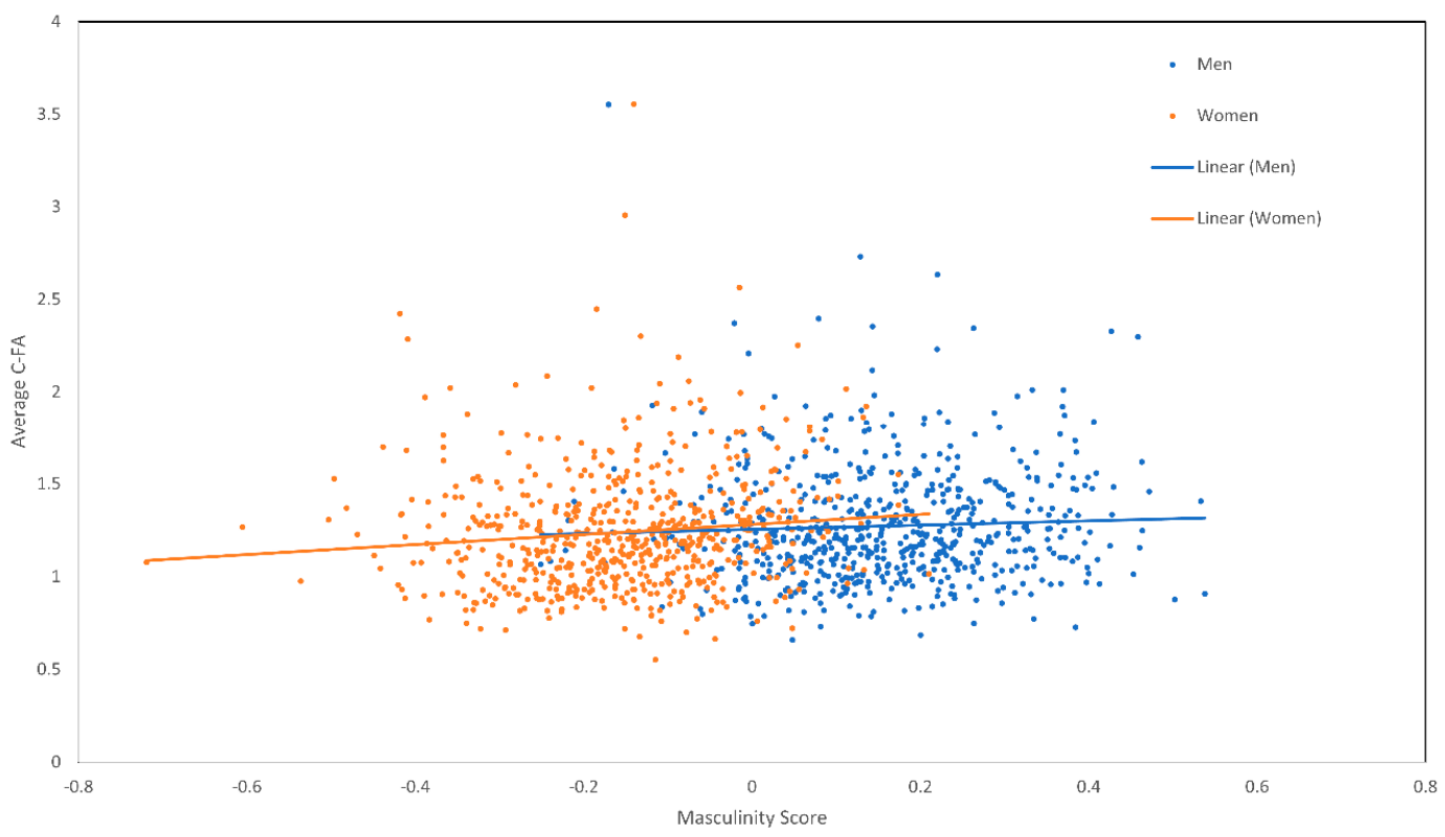

Figure 3. Correlation between average C-FA and masculinity scores in men and women.

The results of the Canonical Correlation Analysis revealed similar patterns (Table 2). In women, the canonical variable of asymmetry showed a statistically significant correlation with sexual dimorphism, with the average C-FA having the highest effect on the masculinity scores. In men, however, similar to the results of the univariate analysis, no significant correlation between the masculinity scores and the canonical variable for asymmetry was found. 
Table 2. Results of Canonical Correlation Analysis for measures of asymmetry and sexual dimorphism, for men and women separately. The results of the significance test of canonical dimensions are shown in the first row of each table. The second row shows the standardized canonical coefficients for each measure of asymmetry contributing to the canonical variable.

\begin{tabular}{cccccccc}
\hline \multirow{3}{*}{ Men } & Canonical Correlation & Wilks' Lambda & F Statistic & df1 & df2 & $p$-Value \\
\cline { 2 - 7 } & 0.12 & 0.9835 & 1.7349 & 6 & 623 & 0.1104 \\
\cline { 2 - 7 } & Average C-FA & PC1 & PC2 & PC3 & PC4 & PC5 \\
\cline { 2 - 7 } & $>0.3062$ & 0.5564 & 0.4775 & 0.2926 & -0.4044 & -0.1972 \\
\hline \multirow{3}{*}{ Women } & Canonical Correlation & Wilks' Lambda & F Statistic & df1 & df2 & $p$-Value \\
\cline { 2 - 8 } & 0.15 & 0.9754 & 2.6169 & 6 & 623 & 0.0163 \\
\cline { 2 - 8 } & Average C-FA & PC1 & PC2 & PC3 & PC4 & PC5 \\
\cline { 2 - 7 } & 0.6955 & 0.2750 & 0.3655 & 0.4219 & 0.3549 & 0.0882 \\
\hline
\end{tabular}

\section{Discussion}

Studying the dataset of 3D facial scans of men and women showed that, in women, the average facial FA shows a significant correlation with the masculinity score $(r=0.12$, $p=0.002$ ). The multivariate analysis of the measures using CCA also unraveled a similar pattern. This means that feminine women are more symmetrical on average (show less FA) compared to women with less femininity. The fact that none of the PCs in the C-FA space showed any correlation with the masculinity scores means that none of the dimensions of FA are prominent in showing the effects of DI; however, the accumulative effect of all of the dimensions leads to a meaningful correlation with masculinity scores. In men, however, none of the PCs of the C-FA space, the average C-FA, or the canonical variable of asymmetry were significantly correlated with masculinity scores (Tables 1 and 2). Based on these results, it is safe to assume that the other dimensions of the C-FA space (PC6 and after) would also not contain any meaningful correlations with masculinity, as they represent less variation of C-FA compared to the first 5 PCs. The individual measure of DA (F-DA) also did not show any correlation with masculinity in men or women.

Testosterone is believed to have a greater impact on immune function than estrogen, making sexually dimorphic features more costly for men in the ICHH context [34]. Therefore, if we assume that FA and masculinity both index underlying genetic quality, we expect a stronger correlation between FA and masculinity in men. However, we did not find any significant correlation between FA and masculinity in men. This means that our results fall of the in line with Puts (2010), supporting the notion that sexually-selected traits do not necessarily signal immunocompetence, and a correlation between FA and masculinity is not expected in men. Zaidi et al. (2019) [35] reported similar results by studying the correlation between genetic markers of immunocompetence and facial masculinity in a large sample of men and women.

On the other hand, the significant correlation found between FA and sexual dimorphism in women is, in fact, in line with ICHH. This means that symmetry and femininity in women could possibly both be indicators of genetic quality. Additionally, studies have reported a more robust association between attractiveness and sexual dimorphism in women than in men, which suggests an association with health measures [18,36]. However, considering that we found no correlation in men (even though ICHH predicts a stronger correlation in men), as well as the results reported by Zaidi et al. (2019), the found correlation could alternatively be attributed to another common underlying mechanism, such as fertility [17,37-39]. Additionally, the fact that the average shape FA correlates to masculinity, while the F-DA measure does not, suggests that the variation in the DA direction among individuals may reflect a different process than developmental instability.

Another possible explanation for the lack of correlation (or the weak correlation in women) between FA and masculinity could be that both traits are poor measures for genetic quality. No strong link has been found between FA or masculinity and general health, 
especially in men [21]. This also justifies the poor correlation between FA or masculinity and attractiveness that was discussed in the introduction.

Currently, most of the literature on this subject has focused its attention on men (perhaps due to the expected stronger correlation). As we have found correlations between FA and masculinity in women, and not in men, we suggest that more studies on women could help to unravel the possible quality that links FA and masculinity. In conclusion, we did not find strong evidence that masculinity and FA in human faces are signals of genetic quality, or that they are correlated, though further investigation in women could be informative.

Author Contributions: Conceptualization, O.E., S.V.D. and P.C.; methodology, S.V.D., P.C., O.E. and E.V.A.; software, O.E.; validation, O.E.; formal analysis, O.E.; investigation, O.E.; resources, S.M.W., M.L.M., S.W., M.D.S.; data curation, O.E.; writing—original draft preparation, O.E.; writing-review and editing, all authors; visualization, O.E.; supervision, S.V.D. and P.C., All authors have read and agreed to the published version of the manuscript.

Funding: This research was funded by the National Institute of Dental and Craniofacial Research (U01-DE020078, R01-DE016148 and R01-DE027023), Center for Human Evolution and Development at Penn State, Science Foundation of Ireland Walton Fellowship (04.W4/B643), US National Institute of Justice (2008-DN-BX-K125), US Department of Defense, University of Illinois Interdisciplinary Innovation Initiative Research Grant, National Institute of Justice (2015-R2-CX-0023 and 2014-DN-BX-K031).

Institutional Review Board Statement: The study was conducted according to the guidelines of the Declaration of Helsinki, and approved by the Institutional Review Board (or Ethics Committee) of University of Pittsburgh (IRB PRO09060553 and RB0405013); UT Health Committee for the Protection of Human Subjects (HSC-DB-09-0508); Seattle Children's Hospital (IRB 12107); University of Iowa Human Subjects (IRB 200912764 and 200710721); Urbana-Champaign, IL (IRB 13103); New York, NY (IRB 45727); Twinsburg, OH (IRB 2503); State College, PA (IRB 44929 and 4320); Austin, TX (IRB 44929); and San Antonio, TX (IRB 1278); Indiana University Purdue University Indianapolis (IRB 1409306349).

Informed Consent Statement: Informed consent was obtained from all subjects involved in the study.

Data Availability Statement: The developed algorithms used to perform this analysis are available in the following GitHub repository: https://github.com/omidek/FA_calculation/. We are unable to provide the raw facial scans' data that are part of the Penn State University dataset because these data are highly identifiable in nature and are in legal and ethical violation of the informed consent obtained from the participants. Interested and qualified researchers may send requests for a more confined sharing of the data to the authors. 3D surface images gathered at the University of Pittsburgh for the 3D Facial Norms cohort are available through the FaceBase Consortium (www.facebase.org) under accession number FB00000491.01, or at: https://www.facebase.org/data/record/\#1/isa: dataset/accession=FB00000491.01.

Conflicts of Interest: The authors declare no conflict of interest.

\section{References}

1. Gangestad, S. Facial masculinity and fluctuating asymmetry. Evol. Hum. Behav. 2003, 24, 231-241. [CrossRef]

2. Brown, W.M.; Price, M.E.; Kang, J.; Pound, N.; Zhao, Y.; Yu, H. Fluctuating asymmetry and preferences for sex-typical bodily characteristics. Proc. Natl. Acad. Sci. USA 2008, 105, 12938-12943. [CrossRef]

3. Little, A.C.; Jones, B.C.; Debruine, L.M. Facial attractiveness: Evolutionary based research. Philos. Trans. R. Soc. B Biol. Sci. 2011, 366, 1638-1659. [CrossRef]

4. Koehler, N.; Simmons, L.W.; Rhodes, G.; Peters, M. The relationship between sexual dimorphism in human faces and fluctuating asymmetry. Proc. R. Soc. Lond. Ser. B Biol. Sci. 2004, 271. [CrossRef] [PubMed]

5. Klingenberg, C.P. A developmental perspective on developmental instability: Theory, models and mechanisms. In Developmental Instability: Causes and Consequences; Polak, M., Ed.; Oxford University Press: Oxford, UK, 2003; pp. 14-34. ISBN 9780195143454.

6. Graham, J.; Özener, B. Fluctuating Asymmetry of Human Populations: A Review. Symmetry 2016, 8, 154. [CrossRef]

7. Van Dongen, S.; Gangestad, S.W. Human fluctuating asymmetry in relation to health and quality: A meta-analysis. Evol. Hum. Behav. 2011, 32, 380-398. [CrossRef] 
8. Lens, L.; Van Dongen, S. Fluctuating and directional asymmetry in natural bird populations exposed to different levels of habitat disturbance, as revealed by mixture analysis. Ecol. Lett. 2008, 3, 516-522. [CrossRef]

9. Leary, R.F.; Allendorf, F.W. Fluctuating asymmetry as an indicator of stress: Implications for conservation biology. Trends Ecol. Evol. 1989, 4, 214-217. [CrossRef]

10. Parés-Casanova, P.M.; Esteve-Puig, C. Directional and fluctuating asymmetries in domestic pig skulls. Research 2014, 1. [CrossRef]

11. Mitteroecker, P.; Windhager, S.; Müller, G.B.; Schaefer, K. The Morphometrics of "Masculinity" in Human Faces. PLoS ONE 2015, 10, e0118374. [CrossRef]

12. Thornhill, R.; Moller, A.P. Developmental stability, disease and medicine. Biol. Rev. 2007, 72, 497-548. [CrossRef]

13. Folstad, I.; Karter, A.J. Parasites, Bright Males, and the Immunocompetence Handicap. Am. Nat. 1992, 139, 603-622. [CrossRef]

14. Roberts, M.L.; Buchanan, K.L.; Evans, M.R. Testing the immunocompetence handicap hypothesis: A review of the evidence. Anim. Behav. 2004, 68, 227-239. [CrossRef]

15. Jones, B.C.; Hahn, A.C.; Fisher, C.I.; Wang, H.; Kandrik, M.; Han, C.; Fasolt, V.; Morrison, D.; Lee, A.J.; Holzleitner, I.J.; et al. No Compelling Evidence that Preferences for Facial Masculinity Track Changes in Women's Hormonal Status. Psychol. Sci. 2018, 29, 996-1005. [CrossRef]

16. Gray, A.W.; Boothroyd, L.G. Female facial appearance and health. Evol. Psychol. 2012, 10, 66-77. [CrossRef]

17. Law Smith, M.J.; Perrett, D.I.; Jones, B.C.; Cornwell, R.E.; Moore, F.R.; Feinberg, D.R.; Boothroyd, L.G.; Durrani, S.J.; Stirrat, M.R.; Whiten, S.; et al. Facial appearance is a cue to oestrogen levels in women. Proc. R. Soc. B Biol. Sci. 2006, 273, 135-140. [CrossRef]

18. Thornhill, R.; Gangestad, S.W. Facial sexual dimorphism, developmental stability, and susceptibility to disease in men and women. Evol. Hum. Behav. 2006, 27, 131-144. [CrossRef]

19. Grammer, K.; Thornhill, R. Human (Homo sapiens) facial attractiveness and sexual selection: The role of symmetry and averageness. J. Comp. Psychol. 1994, 108, 233-242. [CrossRef]

20. Mogilski, J.K.; Welling, L.L.M. The Relative Importance of Sexual Dimorphism, Fluctuating Asymmetry, and Color Cues to Health during Evaluation of Potential Partners' Facial Photographs: A Conjoint Analysis Study. Hum. Nat. 2017, 28, 53-75. [CrossRef]

21. Gangestad, S.W.; Thornhill, R. The evolutionary psychology of extrapair sex: The role of fluctuating asymmetry. Evol. Hum. Behav. 1997, 18, 69-88. [CrossRef]

22. Jones, B.; Little, A.; Penton-Voak, I.; Tiddeman, B..; Burt, D.; Perrett, D. Facial symmetry and judgements of apparent health. Evol. Hum. Behav. 2001, 22, 417-429. [CrossRef]

23. DeBruine, L.M.; Jones, B.C.; Little, A.C.; Boothroyd, L.G.; Perrett, D.I.; Penton-Voak, I.S.; Cooper, P.A.; Penke, L.; Feinberg, D.R.; Tiddeman, B.P. Correlated preferences for facial masculinity and ideal or actual partner's masculinity. Proc. R. Soc. B Biol. Sci. 2006, 273, 1355-1360. [CrossRef] [PubMed]

24. Little, A.C.; Hancock, P.J.B. The role of masculinity and distinctiveness on the perception of attractiveness in human male faces. Br. J. Psychol. 2002, 93, 451-464. [CrossRef]

25. Swaddle, J.P.; Reierson, G.W. Testosterone increases perceived dominance but not attractiveness in human males. Proc. R. Soc. Lond. Ser. B Biol. Sci. 2002, 269, 2285-2289. [CrossRef]

26. DeBruine, L.; Jones, B.C.; Frederick, D.A.; Haselton, M.G.; Penton-Voak, I.S.; Perrett, D.I. Evidence for Menstrual Cycle Shifts in Women's Preferences for Masculinity: A Response to Harris (in Press) "Menstrual Cycle and Facial Preferences Reconsidered". Evol. Psychol. 2010, 8, 147470491000800. [CrossRef]

27. Little, A.C.; Jones, B.C.; DeBruine, L.M.; Feinberg, D.R. Symmetry and sexual dimorphism in human faces: Interrelated preferences suggest both signal quality. Behav. Ecol. 2008, 19, 902-908. [CrossRef]

28. Van Dongen, S.; Ekrami, O.; Claes, P. Lack of Correlation between Facial Sexual Dimorphism, Fluctuating Asymmetry and Self-Perceived Attractiveness in Men and Women. Symmetry 2020, 12, 236. [CrossRef]

29. Van Dongen, S. Fluctuating asymmetry and masculinity/femininity in humans: A meta-analysis. Arch. Sex. Behav. 2012, 41, 1453-1460. [CrossRef]

30. Puts, D.A. Beauty and the beast: Mechanisms of sexual selection in humans. Evol. Hum. Behav. 2010, 31, 157-175. [CrossRef]

31. Ekrami, O.; Claes, P.; White, J.D.; Zaidi, A.A.; Shriver, M.D.; Van Dongen, S. Measuring asymmetry from high-density 3D surface scans: An application to human faces. PLoS ONE 2018, 13, e0207895. [CrossRef]

32. Ekrami, O.; Claes, P.; White, J.D.; Weinberg, S.M.; Marazita, M.L.; Walsh, S.; Shriver, M.D.; Van Dongen, S. A multivariate approach to determine the dimensionality of human facial asymmetry. Symmetry 2020, 12. [CrossRef]

33. Van Dongen, S. Are smarter people (a bit) more symmetrical? A matter of how to adjust for publication bias? J. Negat. Results 2012, 9, 1-14.

34. Little, A.C.; Jones, B.C.; Waitt, C.; Tiddeman, B.P.; Feinberg, D.R.; Perrett, D.I.; Apicella, C.L.; Marlowe, F.W. Symmetry Is Related to Sexual Dimorphism in Faces: Data Across Culture and Species. PLoS ONE 2008, 3, e2106. [CrossRef] [PubMed]

35. Zaidi, A.A.; White, J.D.; Mattern, B.C.; Liebowitz, C.R.; Puts, D.A.; Claes, P.; Shriver, M.D. Facial masculinity does not appear to be a condition-dependent male ornament and does not reflect MHC heterozygosity in humans. Proc. Natl. Acad. Sci. USA 2019, 116, 1633-1638. [CrossRef] [PubMed]

36. Penton-Voak, I.S.; Jacobson, A.; Trivers, R. Populational differences in attractiveness judgements of male and female faces. Evol. Hum. Behav. 2004, 25, 355-370. [CrossRef] 
37. Manning, J.; Scutt, D.; Lewis-Jones, D. Developmental Stability, Ejaculate Size, and Sperm Quality in Men. Evol. Hum. Behav. 1998, 19, 273-282. [CrossRef]

38. Johnston, V. Female facial beauty: The fertility hypothesis. Pragmat. Cogn. 2000, 8, 107-122. [CrossRef]

39. Moore, F.R.; Law Smith, M.J.; Taylor, V.; Perrett, D.I. Sexual dimorphism in the female face is a cue to health and social status but not age. Pers. Individ. Dif. 2011, 50, 1068-1073. [CrossRef] 